\title{
Aspects Regarding Ageing of Compounds Based on Natural Rubber and Plasticized Starch
}

\begin{abstract}
MARIA DANIELA STELESCU1', ELENA MANAILA2*, GABRIELA CRACIUN², MIHAI GEORGESCU ${ }^{1}$
${ }^{1}$ National Research and Development Institute for Textiles and Leather, Division Leather and Footwear Research Institute, 93 Ion Minulescu Str., 031215, Bucharest, Romania

${ }^{2}$ National Institute for Laser, Plasma and Radiation Physics, Electron Accelerators Laboratory, 409 Atomistilor Str., 077125, Magurele, Romania

This paper presents a study on the behaviour of composites based on natural rubber and plasticized starch after aging under temperate climate conditions. Natural rubber blends containing different amounts of glycerine-plasticized starch as biodegradable filler were made. Analysis of samples after being kept for 1 year in temperate weather conditions shows a change in the surface of vulcanizates due to the influence of atmospheric factors. Surface oxidation and degradation was highlighted by: FTIR analysis (appearance of $-\mathrm{OH},-\mathrm{COOH}$ groups, etc.), SEM microscopy (appearance of cracks on the surface), immersion in water. The degradation of the materials is also highlighted by the decrease of the physical-mechanical properties, the gel fraction and crosslinking degree. The best aging behaviour was observed in the mixture containing a low amount of biodegradable starch and the worst behaviour was that of the control starch-free mixture.
\end{abstract}

Keywords: polymer composites, natural rubber, starch, degradation, properties

Products made from cured rubber undergo various physical and chemical influences over time, causing significant changes in rubber properties. These changes have led to the introduction of the notion of ageing. Vulcanizate ageing in the atmosphere is a destructive form of simultaneous action of aggressive factors such as oxygen, ozone, light, heat and mechanical stress causing degradation over time of vulcanizates if they are not provided with effective protection [1].

In order to evaluate the relative resistance of rubber to deterioration with the passing of time, accelerated ageing and heat resistance tests can be carried out. For this purpose, rubber is subjected to controlled deterioration conditions, over determined periods of time, and then characteristics are measured and compared with the properties of unaged rubber. Accelerated ageing does not reliably and under all circumstances reproduce changes caused by natural ageing [2] .

This paper makes a comparison between accelerated ageing and ageing under temperate climate conditions of mixtures based on natural rubber and plasticized starch.

It is known that natural rubber (NR) aging in air affects its properties. Due to the high level of unsaturation of NR, it can be easily attacked by oxygen. It was found that the oxidation of NR is further accelerated by heat, light, impurities, and mechanical strainstress [3].

In this study, various amounts of biodegradable filler, namely starch plasticized with glycerine, were added to natural rubber mixtures. Ageing of starch-based materials leads to increased hardness, depending on their physical condition and environmental conditions. This increase in hardness may be linked to two processes. If materials are stored in a glassy state $(\mathrm{Tg}<$ storage temperature) increased rigidity is generally associated with a structural relaxation phenomenon or physical ageing that occurs in the material. If they are stored in an amorphous state ( $\mathrm{Tg}$ $>$ storage temperature), increased hardness is usually linked to a molecular reorganization process known as retrogradation. In 1968, Collison [4] defined retrogradation as a crystallization process occurring due to the very strong tendency to form hydrogen bonds between hydroxyl groups on adjacent starch molecules. Retrogradation can eliminate water from the polymer network. This process is known as syneresis. Retrogradation is directly linked to the ageing of bread [5-6].

Starch introduced in the rubber mixtures was plasticized with a polyol - glycerine. Although the main functionality of these compounds is their plasticizing effect, papers were published suggesting that polyols may interact with the polymer chains of starch, reducing the retrogradation rate of these materials [7].

Several research studies have highlighted the influence of biodegradable fillers such as starch on improving rheological and physical-mechanical characteristics of some mixtures based on natural rubber [8-9]. Studies on ageing behaviour in temperate climate conditions or accelerated ageing of these types of mixtures have not been carried out yet.

\section{Experimental part}

The following materials were used in this study:

Natural rubber (NR) Crep from Sangtvon Rubber Ltd, in the form of white rubber sheets, Mooney viscosity 67.64 $\mathrm{ML}\left(1^{\prime}+4^{\prime}\right) 100^{\circ} \mathrm{C}$, volatile matter content of $0.5 \%$, nitrogen content $0.45 \%$, ash content of $0.25 \%$, impurity content of $0.026 \%$;

Starch - produced by Lach-Ner - soluble potato starch (water insoluble substances $0.28 \%$; loss on drying $16.9 \%$, easily biodegradable: $\mathrm{BOD}_{5}-0.6 \mathrm{~g} / \mathrm{g}$ - and COD $-1.2 \mathrm{mg} / \mathrm{g}$ );

Glycerine produced by $S^{5}$ Chimreactiv SRL (free acidity $0.02 \%$, density $1.26 \mathrm{~g} / \mathrm{cm}^{3}$, purity $\left.99.5 \%\right)$;

Richon IPPD antioxidant (4010 NA) N-isopropyl - Nphenyl - phenylene diamine, $98 \%$ purity, molecular mass 493.6374;

For crosslinking blends, the following were used: di(tertbutilperoxi-izopropil)benzen Perkadox 14-40B-GB (density $160 \mathrm{~g} / \mathrm{cm}^{3}, 3.8 \%$ active oxygen content, $40 \%$ peroxide content, $\mathrm{pH}$ 7) and polyfunctional monomer 
trimethylolpropane trimethacrylate Luvomaxx TMPT DL 75 (TMPT) (22 \% ash, pH 9.2, density $1.36 \mathrm{~g} / \mathrm{cm}^{3}, 75 \pm 3 \%$ active ingredient);

\section{Plasticizing Starch}

Starch is dried at $80^{\circ} \mathrm{C}$ for $24 \mathrm{~h}$. Starch (65\%) are mixed with glycerine (35\%) for $7 \mathrm{~min}$ at $2000 \mathrm{rpm}$ and $70^{\circ} \mathrm{C}$ until a homogenous mixture is obtained. It is left for $16 \mathrm{~h}$ in a dry place for stabilization. Starch was plasticized to improve its processability and other properties [10].

\section{Obtaining compounds based on natural rubber and plasticized starch}

Mixtures were obtained by mixing on a roll mill. First,

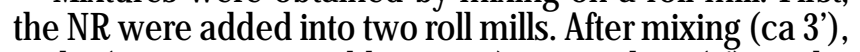
1 phr (parts per 100 rubber parts) antioxidant (2'); 0 phr, $15.4 \mathrm{phr}, 30.8 \mathrm{phr}$ and $46.2 \mathrm{phr}$ glycerine-plasticized starch (5-15'), respectively, and lastly the vulcanizing agent: $8 \mathrm{phr}$ peroxide and 3 phrTMPT are added into the compounding $\left(2^{\prime}\right)$. The mixture is homogenised and taken off the roll mill in the form of a sheet about $2 \mathrm{~mm}$ thick $\left(3^{\prime}\right)$. Working parameters: friction $1: 1,1$, temperature $55-75^{\circ} \mathrm{C}$, time 15 $25 \mathrm{~min}$.

Preparation of Sample: The test specimen sheets of all compounds were produced using compression moulding. The temperature of the compression moulding machine was kept constant at $165^{\circ} \mathrm{C}$. The time taken to produce the specimen sheets was based on the curing time $\left(t_{90}\right)$ from the curing testing (12-15min) [9].

\section{Laboratory Tests}

Mechanical properties of samples were measured on a Schopper tensile tester with a nominal rate of the traverse of the moving grip of $460 \mathrm{~mm} / \mathrm{min}$. Modulus at $100 \%$ strain, tensile strength, and elongation atbreak tests were carried out according to the conditions described in ISO 37/2012, on dumb-bell shaped specimens of type 2 (the precision and the uncertainties of the test are \pm 0.64 for tensile strength and \pm 2.95 for elongation at break). Tearing strength tests were carried out using angular test pieces (type II) according to SR EN 12771/2003. Hardness of materials was measured using the Shore $A$ scale with samples of $6 \mathrm{~mm}$ thickness, by using a hardener tester according to ISO 7619-1/2011 (the precision and the uncertainties of the test are \pm 0.05 ). Elasticity was evaluated with a Schob test machine using $6 \mathrm{~mm}$ thick samples, according to ISO 4662/2009.

Resistance to swelling by liquids was determined according to ISO 1817/2005 by the change in mass using the following method: the test pieces of known weight were immersed in water and toluene, in diffusion test bottles and kept at room temperature for $72 \mathrm{~h}$. After immersion, the samples were taken out from the solvents, and the wet surfaces were quickly dried using a tissue paper and reweighted.

To calculate the percentage change in mass $\Delta m_{100}$ the following formula was used:

$$
\Delta m_{100}=\frac{m_{i}-m_{0}}{m_{0}} \times 100
$$

where $m_{0}$ is the initial mass of the test piece and $m_{i}$ is the mass of the test piece after immersion.

Report the result as the median value for the three test pieces. The precision and the uncertainties of the test are \pm 0.04 .

The densities of elastomer samples were measured according to ISO 2781/2010 (the precision and the uncertainties of the test are \pm 0.09 )
Accelerated ageing trial was done according to SR ISO188/20010 using the hot air circulation oven method. Similar samples to those used for tensile testing and for hardness determination were used. Test duration was of 7 days and temperature of $70 \pm 1^{\prime \prime \prime} \mathrm{C}$. The results were compared with those from samples not subjected to ageing.

In this paper, ageing of samples was determined for a period of 1 year under temperate climate conditions. The period when samples were subjected to degradation was: 30 august 2016-30 august 2017, in Bucharest, Romania. Temperature variation was between $+39-(-) 20^{\circ} \mathrm{C}$. Romania has a temperate continental climate in transition, marked by some oceanic, continental, Scandinavian-Baltic and sub-Mediterranean influences, characterized by mild winters and a stronger rainfalls (particularly in autumn) [11].

\section{Gel fraction determination}

Crosslinked NR (with and without starch) was analysed to determine mass fraction of insoluble NR in the samples (gel fraction). The samples were swollen in toluene for 72 $h$ to eliminate cleaved fragments and unreacted materials. Samples were weighed again. The gel fraction was calculated using the following relation (2):

$$
\text { Gelfraction }=\frac{m_{s}}{m_{i}} \times 100
$$

where $m_{s}$ and $m_{i}$ are the mass of the dry sample after swelling and the mass of the sample before swelling [1214].

Crosslinking density $(v)$ of samples was determined based on equilibrium measurements in a solvent (toluene at $23-25^{\circ} \mathrm{C}$ ) by applying the modified Flory-Rehner equation for tetrafunctional networks. Samples (thickness of $2 \mathrm{~mm}$ ) were initially weighed $\left(m_{i}\right)$ and immersed in toluene for 72 h. Swollen samples were then carefully wiped with tissue paper to remove excess solvent before weighing $\left(m_{0}\right)$ in weighing ampoules to avoid evaporation of toluene during weighing. All samples were air dried for 6 days and in a laboratory oven at $80^{\circ} \mathrm{C}$ for $12 \mathrm{~h}$ to completely remove the solvent. Finally, samples were weighed again $\left(m_{s}\right)$, and volume fractions of the polymer in the samples swollen to equilibrium $v_{2 m}$ were determined from the swelling ratio, G, as follows:

where:

$$
v_{2 m}=\frac{1}{1+G}
$$

$$
G=\frac{m_{g}-m_{s}}{m_{s}} \times \frac{\rho_{r}}{\rho_{s}} ;
$$

$\rho_{r}$ and $\rho_{s}$ are densities of rubber samples and solvent (toluene density was $0.866 \mathrm{~g} / \mathrm{cm}^{3}$ ).

Crosslinking density, $\mathrm{v}$, was determined using the FloryRehner equation:

$$
v=-\frac{\operatorname{Ln}\left(1-v_{2 m}\right)+v_{2 m}+\chi_{12} v_{2 m}^{2}}{V_{1}\left(v_{2 m}^{1 / 3}-\frac{v_{2 m}}{2}\right)}
$$

where $V_{1}$ is the molar volume of the solvent $\left(106.5 \mathrm{~cm}^{3} /\right.$ mol for toluene), the volume fraction of the polymer in the sample swollen to equilibrium, and $\chi_{12}$ the FloryHuggins polymer-solvent interaction parameter (for natural rubber - toluene $\chi_{12}$ the value is 0.393) [12-13].

Rubber-filler interactions: were analyzed using Kraus equation [15]: 


$$
V_{r o} / V_{r f}=1-m \frac{f}{1-f}
$$

where $V_{r}$ and $V_{\text {rf }}$ are the volume fractions of rubber in the gum vulcanizate and in fibre filled swollen sample, respectively, $f$ the volume fraction of filler and $m$ the filler polymer interaction parameter. The volume fraction of rubber in the swollen sample $V_{\text {rf }}$, was calculated by the expression:

$$
V_{r f}=\frac{\left[(D-F T) / \rho_{r}\right]}{\left[(D-F T) / \rho_{r}\right]+\left(A_{0} / \rho_{S}\right)}
$$

where $\rho_{r}$ and $\rho_{c}$ are the densities of rubber samples and solvent $\left(0.94-1.0 \mathrm{~g} / \mathrm{cm}^{3}\right.$ for natural rubber and $0.866 \mathrm{~g} / \mathrm{cm}^{3}$ for toluene), respectively, $D$ the deswollen weight of the test specimen (dry weight), $F$ the weight fraction of the insoluble components, $T$ the weight of the specimen and $A_{0}$ the weight of the absorbed solvent at equilibrium swelling.

\section{Fourier transform infrared spectroscopy (FTIR).}

Changes of the chemical structure of samples were highlighted using a FTIR spectrophotometer - TENSOR 27 (Bruker, Germany) by ATR measurement method. Samples spectra are the average of 30 scans realized in absorption in the range of $4000-600 \mathrm{~cm}^{-1}$, with a resolution of $4 \mathrm{~cm}^{-1}$. Before analysis, samples were immersed in toluene for 72 $h$ to eliminate uncrosslinked rubber.

\section{Scanning Electron Microscopy (SEM).}

The surface texture of the samples was examined using a scanning electron microscope (FEl/Phillips, USA). All the surfaces were placed on an aluminium mount, sputtered with gold palladium, and then scanned at an accelerating voltage up to $30 \mathrm{kV}$.

\section{Results and discussions}

Variation of physical-mechanical properties depending on the composition and method of testing ageing is presented in figures 1-6. Figure 1 shows a decrease in hardness by $3^{\circ} \mathrm{ShA}$ as a result of ageing for starch-free control mixtures, a decrease in hardness by $3^{\circ} \mathrm{ShA}$ as a result of ageing which may be dues to the decreased degree of rubber crosslinking as a result of ageing. Mixture

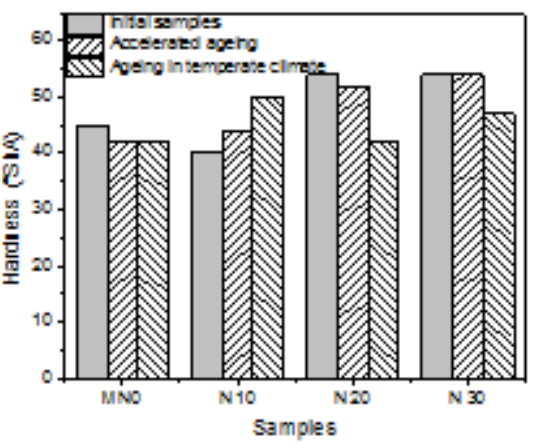

Fig. 1. Hardness variation

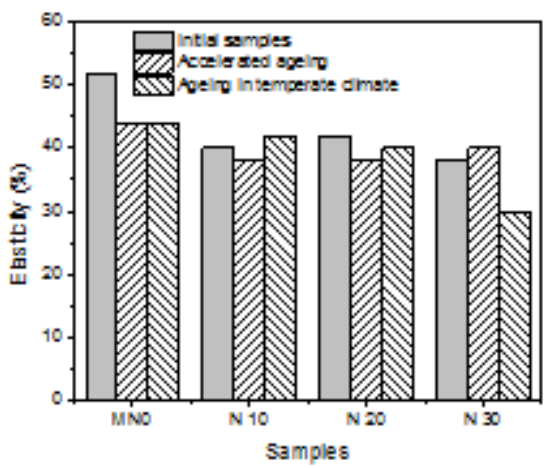

MATERIALE PLASTICE $\bullet 55$ No. $3 \bullet 2018$

Fig. 2. Elasticity variation
N10 (containing $10 \mathrm{phr}$ starch) shows an increased hardness, which may be due to physical ageing / retrogradation of starch existing in the mixture [5-7]. Mixtures N20 (containing $20 \mathrm{phr}$ starch) and N30 (containing $30 \mathrm{phr}$ starch), respectively, show a small variation in hardness as a result of accelerated ageing, while ageing under temperate climate conditions leads to a decrease of $7-12^{\circ} \mathrm{ShA}$. This decrease may be due to the decreased crosslinking degree of mixtures that may be accelerated by the tendency of starch to biodegrade. Elasticity (fig. 2) varies irregularly with the increased amount of starch in the mixtures, for both types of ageing.

Modulus at $100 \%$ elongation and tensile strength (figs. 3-4) decrease significantly both by accelerated ageing and by ageing under temperate climate conditions for 1 year, and the best values after ageing are those obtained for mixture $\mathrm{N} 20$ (decreases of $74.6 \%$ ). These results may indicate a degradation of vulcanizates due to meteorological conditions. Similar effects for natural rubber vulcanizates were reported by R.P. Brown and T. Butler. [16]. Elongation at break (fig. 5) decreases by max $23 \%$ for accelerated ageing and by $23-77 \%$ for ageing under atmospheric conditions, indicating either an increased crosslinking degree as a result of accelerated ageing at high temperature, or a degradation of elastomers under the action of atmospheric factors. Tear strength (fig. 6) for mixtures subjected to accelerated ageing varied irregularly [+37.5 - (-) 51.5\%], as a result of increased crosslinking

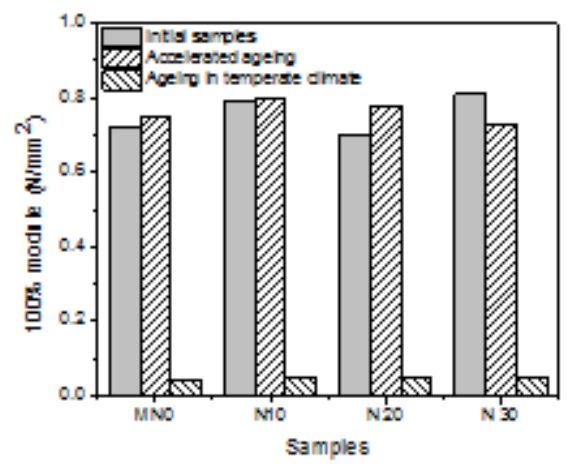

Fig. 3. $100 \%$ modulus variation

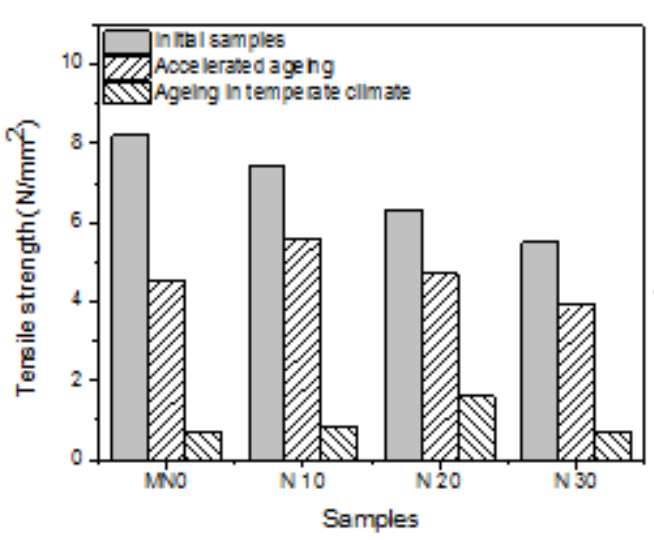

Fig. 4. Tensile strength variation

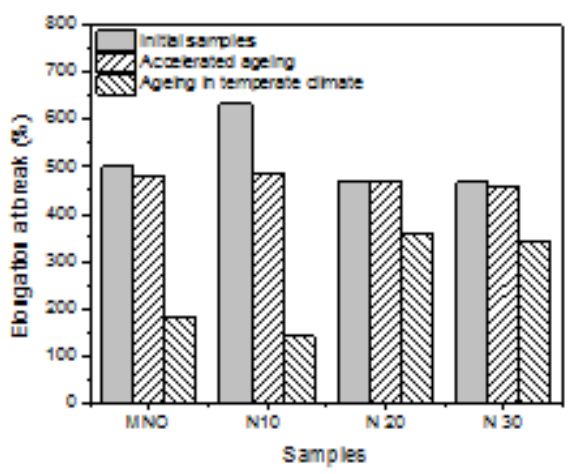

Fig. 5. Elongation 


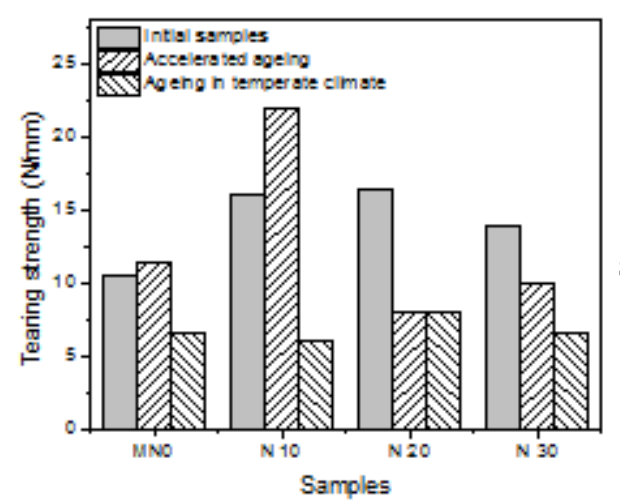

Fig. 6. Tear strength variation

degree by heating, and has decreased by $38.1-62.5 \%$ respectively for mixtures aged under temperate climate conditions for 1 year, as a result of the degradation action of atmospheric factors (low/high temperatures, humidity, impurities, wind, etc.).

\section{Resistance to swelling by liquids}

Mass variation in toluene (table 1) increases by $37.3 \%$ for the control mixture (without starch) and by $2.9-23.7 \%$ for starch mixtures, indicating a better behaviour of mixtures with starch after maintaining under temperate climate conditions for 1 year.

Mass variation in water (table 1) for the control mixture (without starch) has a significant increase (by $657 \%$ mass variation), indicating that the surface was oxidized under the influence of atmospheric factors, forming various groups (aldehydes, ketones, carboxylated acids, alcohols) that absorb water. On the other hand, mixtures with 10 , 20, 30 and 40 phr starch, after 1 year, show only small increases from 5.7 to $51.3 \%$ compared to the initial state, indicating a better behaviour to ageing.

\section{Gel fraction and crosslink density}

Figures 7-8 present values of gel fraction and crosslink density for normal state and after 1 year of ageing under temperate climate conditions. In both cases, the best values were obtained for the mixtures with $10 \mathrm{phr}$ starch (N10), and the highest decreases were obtained for the control mixtures, while the other values range between these two.

Gel fraction values are good (over 95\%), but there is a decrease after 1 year, by $1.35 \%$ for the control mixture (without starch), by $0.69 \%$ for the mixture with 10phr starch (N10), and the other values are found between these two. Similarly, the crosslinking density decreased after ageing

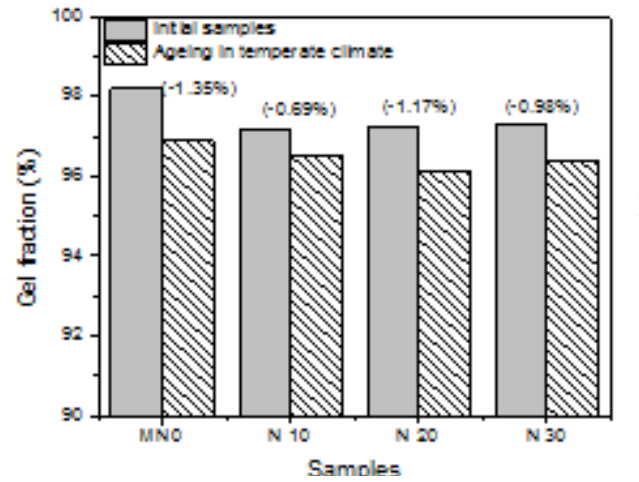

Fig. 7. Gel fraction variation

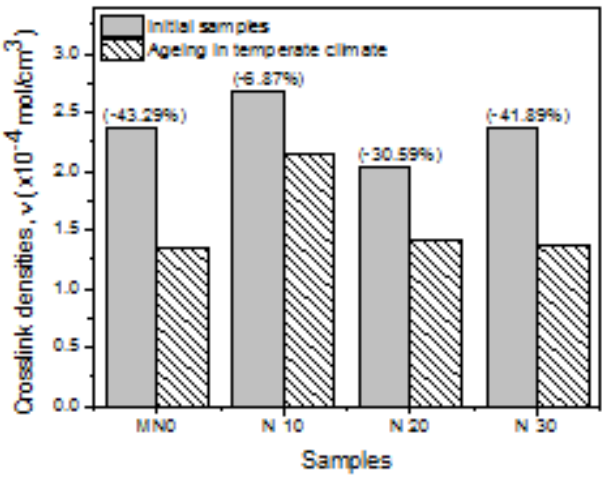

Fig. 8. Crosslink density variation

for 1 year under temperate climate conditions, only in this case there are much higher decreases of values: MNO < $\mathrm{N} 30<\mathrm{N} 20<\mathrm{N} 10$.

In conclusion, the best behaviour to ageing was seen in the mixture containing a low amount of biodegradable filler such as starch and the worst behaviour was that of the control mixture without starch. As a result, starch has led to an improved behaviour to ageing of rubber mixtures, and the best results were obtained for the mixture containing a lower amount of starch.

\section{Rubber-filler interactions}

The rubber-filler interaction degree determined according to the Kraus equation [15] is presented in table 2. The $V_{r} N_{\text {ff }}$ ratio is the swelling restriction degree of rubber due to the presence of starch. The lower and lower values of the $V_{r r} / V_{\text {rf }}$ ratio are associated with an increased adherence between filler (starch) and rubber, according to the Kraus theory and equation. Samples aged for 1 year under temperate climate conditions show decreases of $\mathrm{V}_{\text {rf }}$ compared to initial samples, indicating a higher degree of restrictions. In the case of $\mathrm{N} 10$ samples, $\mathrm{V}_{\text {ff }}$ decreases by $2.74 \%$ and the $\mathrm{V}_{\mathrm{r} 0} / \mathrm{V}_{\mathrm{rf}}$ ratio decreases by $21.86 \%$ after

\begin{tabular}{|c|c|c|c|c|}
\hline \multirow[b]{2}{*}{ Mixture symbol } & \multicolumn{2}{|c|}{ TOLUENE } & \multicolumn{2}{|c|}{ WATER } \\
\hline & Mass variation $\%$ & $\begin{array}{c}\text { Initial/degraded } \\
\text { variation }\end{array}$ & $\begin{array}{c}\text { Mass } \\
\text { variation, \% }\end{array}$ & $\begin{array}{c}\text { Initial/degraded } \\
\text { variation }\end{array}$ \\
\hline $\mathrm{MN}-0$ & 252 & \multirow{2}{*}{$+37.30 \%$} & 0.56 & \multirow{2}{*}{$+657.14 \%$} \\
\hline $\mathrm{MN}-0 / 1$ year & 346 & & 4.24 & \\
\hline N10 & 239 & \multirow{2}{*}{$+2.94 \%$} & 5.56 & \multirow{2}{*}{$+5.76 \%$} \\
\hline N10/1 year & 246 & & 5.88 & \\
\hline $\mathrm{N} 20$ & 258 & \multirow{2}{*}{$+19.77 \%$} & 7.63 & \multirow{2}{*}{$+15.99 \%$} \\
\hline N20/1 year & 309 & & 8.85 & \\
\hline N30 & 236 & \multirow{2}{*}{$+23.73 \%$} & 7.79 & \multirow{2}{*}{$+51.35 \%$} \\
\hline $\mathrm{N} 30 / 1$ year & 292 & & 11.79 & \\
\hline
\end{tabular}

Table 1

MASS VARIATION AFTER $72 \mathrm{~h}$ OF IMMERSION IN TOLUENE AND WATER, RESPECTIVELY

\begin{tabular}{|c|c|c|c|c|}
\hline Samples & \multicolumn{2}{|c|}{$V_{\text {rf }}$} & \multicolumn{2}{c|}{$V_{\text {ro }} V_{\text {rf }}$} \\
\hline & initial & after l year & initial & after l year \\
\hline N10 & 0.2515 & 0.2446 & 1.0632 & 0.8308 \\
\hline N20 & 0.2286 & 0.1959 & 1.1696 & 1.0375 \\
\hline N30 & 0.2352 & 0.2022 & 1.1371 & 1.0052 \\
\hline
\end{tabular}

Table 2

$V_{r f}$ AND $V_{r o} / V_{r f}$ of NR/PLASTICIZED STARCH COMPOSITES DETERMINED IN TOLUENE 


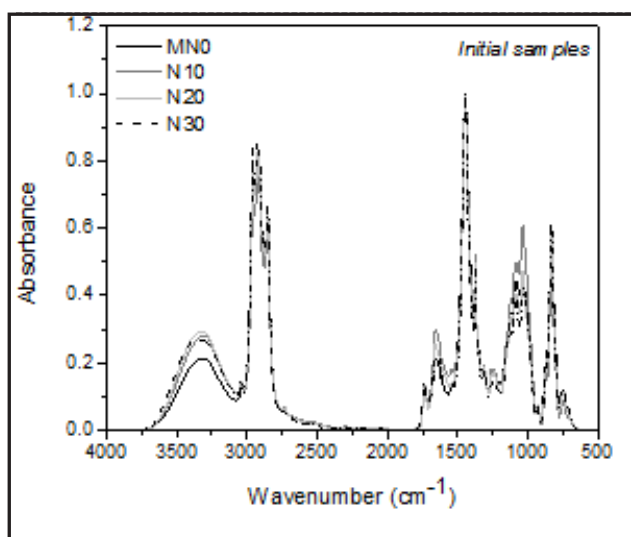

(a)

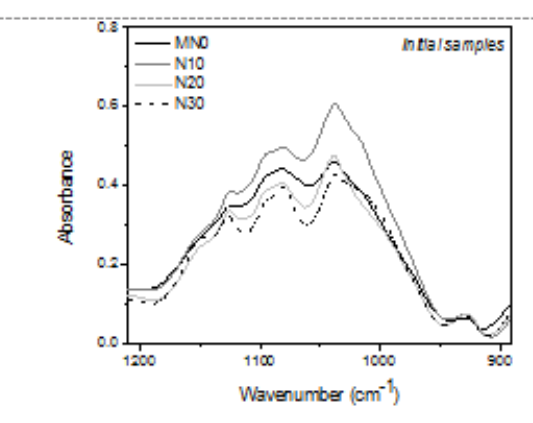

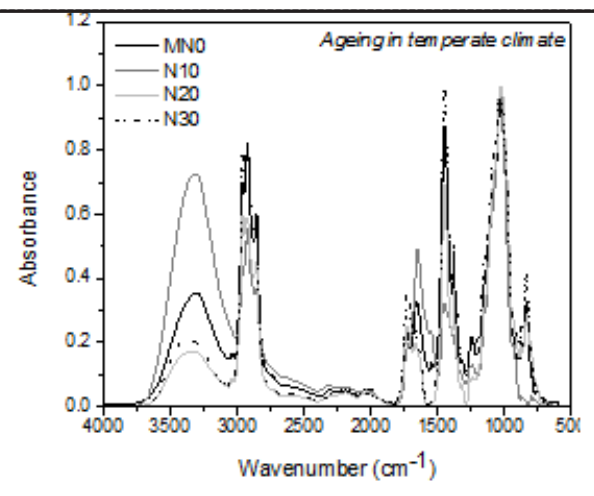

(b)

(c) detail $900-1200 \mathrm{~cm}^{-1}$

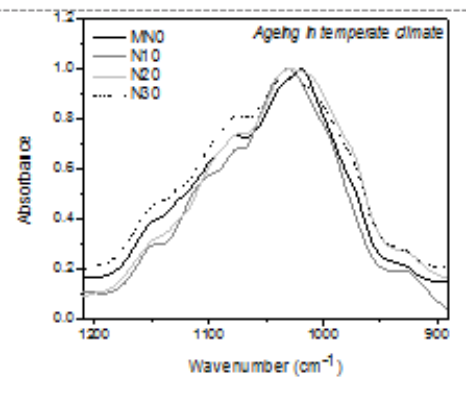

Fig. 9. Infrared spectra in a range of $4000-500 \mathrm{~cm}^{-1}$,

a) initial samples; b) ageing in temperate climate,

(c) detail $900-1200 \mathrm{~cm}^{-1}$,

(d) detail $1400-1750 \mathrm{~cm}^{-1}$

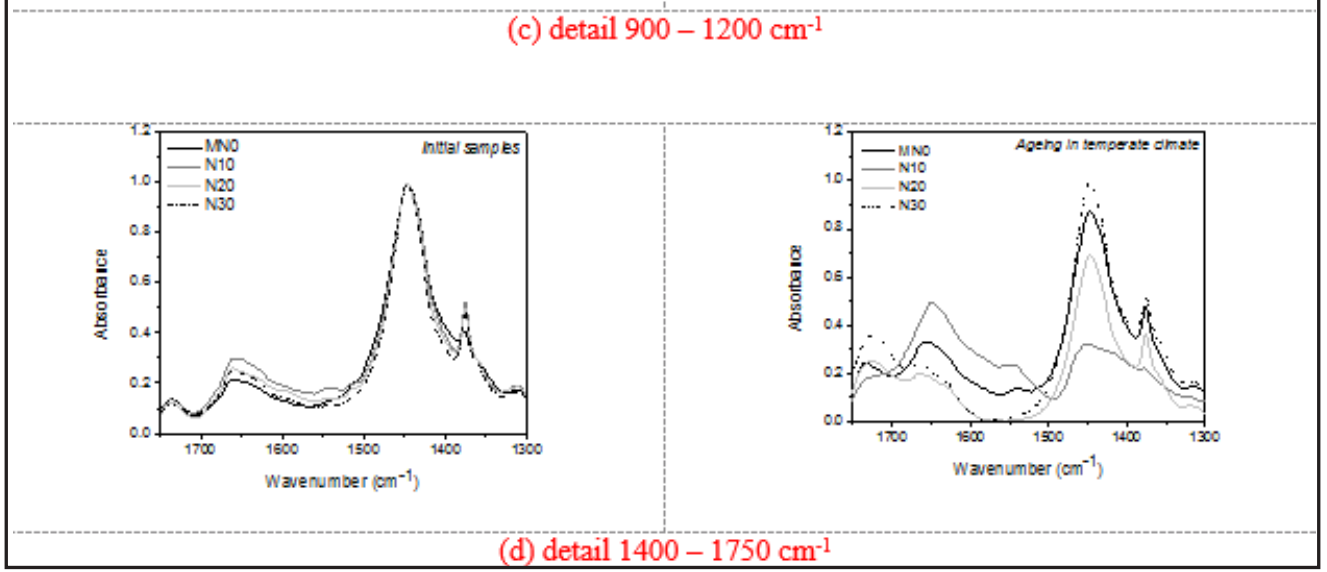

ageing for 1 year, while for samples $\mathrm{N} 20$ and N30, $\mathrm{V}_{\text {r }}$ decreases by 14.3 and $14.03 \%$, respectively, and the $V_{r 0}$ rf $V_{\text {rf }}$ ratio decreases by $11.29 \%$ and $11.6 \%$, respectively.

\section{FTIR study}

Figure 9 shows the infrared spectra and characteristic infrared bands observed (in the region of 4,000-560 $\mathrm{cm}^{-1}$ ) of samples before and after ageing for 1 year under temperate climate conditions. Absorption bands specific to natural rubber are seen: at $830-834 \mathrm{~cm}^{-1}$ corresponding to chemical groups cis $\mathrm{C}=\mathrm{C}$, at $860-885 \mathrm{~cm}^{-1}(\mathrm{~m})$ corresponding to 3,4 addition products of isoprene, at 1370$1375 \mathrm{~cm}^{-1}$ for $-\mathrm{CH}_{3}$, at $1635-1665 \mathrm{~cm}^{-1}$ corresponding to $\mathrm{C}=\mathrm{C}$ [17]. Mixtures containing starch show the common signals for these kinds of polysaccharides, with glucopyranose rings such as $\mathrm{OH}$ bands at $3300-3400 \mathrm{~cm}^{-1}$, $\mathrm{C}-\mathrm{H}$ stretching vibrations of aliphatic groups at 2918-2928 $\mathrm{cm}^{-1}$, adsorbed water signals at 1648-1662- $\mathrm{cm}^{-1}, \mathrm{C}-\mathrm{C}$ and C-O stretching at $1120-1160 \mathrm{~cm}^{-1}$, and $\mathrm{C}-\mathrm{O}-\mathrm{H}$ bending vibration at $1005 \mathrm{~cm}^{-1}$ [18-19].

After degradation by maintaining for 1 year under temperate climate conditions the following are noticed: intensification of bands specific to aldehydes and ketones $\left(1750-1725 \mathrm{~cm}^{-1}\right)$, organic acids $\left(1550-1610 \mathrm{~cm}^{-1}\right)$, ethers
(1050-1150 $\left.\mathrm{cm}^{-1}\right)$, alcohols $\left(3200-3400 \mathrm{~cm}^{-1}\right)$, etc. These results indicate that the ageing process of elastomer samples is accompanied by an oxidative degradation activated by ultraviolet light and heat in the presence of atmospheric oxygen. These oxidative effects occur when oxygen attacks the unsaturated bond from the macromolecular chain of natural rubber as a result of rubber ageing under temperate climate conditions, also reported by other researchers [1, 20-21].

\section{SEM}

To correlate the influence of degradation under temperate climate conditions on the mechanical properties, the morphological aspect of the natural rubber/ plasticized starch composites required evaluation by SEM technique. For SEM analysis, the samples were initially immersed in toluene for $72 \mathrm{~h}$ to remove unvulcanized natural rubber. SEM micrographs of the samples MNO and N10 in initial state and after 1 year, are shown in figures 10a, 10b, 10c and 10d. The SEM micrographs also revealed that the filler - plasticized starch - is uniformly distributed in the natural rubber matrix (figs. $a$ and $c$ ). After ageing for 1 year in temperate climate, due to the degradation phenomenon, changes have occurred on the surface of 


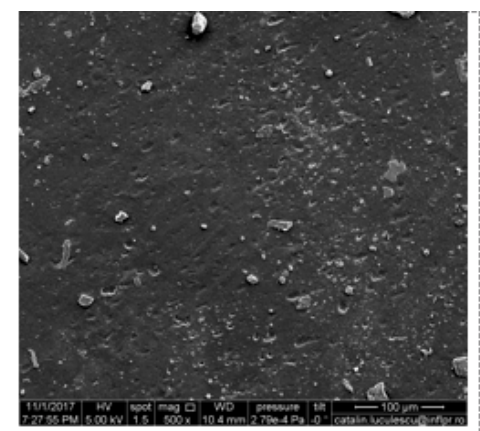

(a) $\mathrm{MN} 0$ - initial

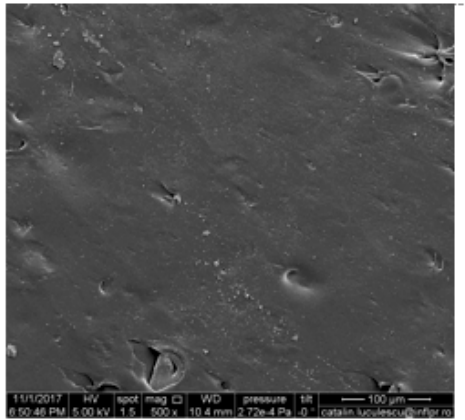

(c) N10 - initial

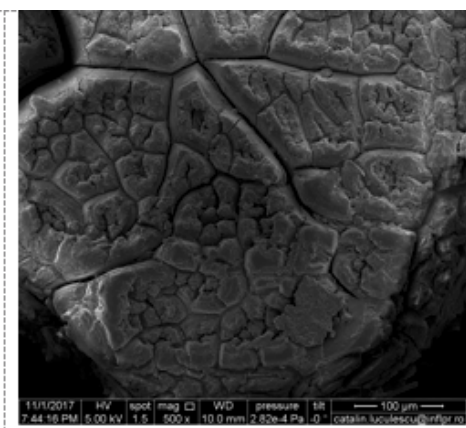

(b) MN0 - after 1 year

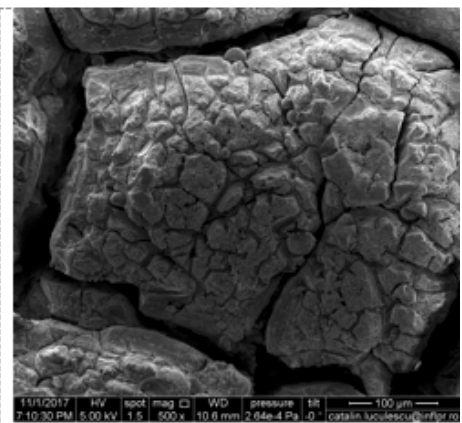

(d) N10 - after 1 year

vulcanizates - cracks and breaks of varied sizes and depths appeared on the surface of the material (figs.10 b and 10d). According to existing research, these have occurred primarily due to the ozone in the atmosphere. At first only the surface of the object is affected by the attack, then degradation progresses, causing a change in physicalmechanical properties, and ultimately leading to a complete break in the object. [1, 21].

Acknowledgements: This research was financed through Nucleu Program 2016-2017 PN 163401 01: Development of biodegradable nanocomposites based on natural rubber, starch and OMMT with applications in the food and pharmaceutical industries supported by Romanian Ministry of Research and Innovation.

\section{Conclusions}

Analysis of characteristics of mixtures based on natural rubber and plasticized starch after maintaining under temperate climate meteorological conditions for 1 year indicates a change in the surface of vulcanizates as a result of atmospheric factors. Oxidation and degradation of surfaces was highlighted by FTIR analysis (presence of $\mathrm{COOH}$ groups, etc.), SEM microscopy (presence of cracks on the surface), immersion in water highlighting the existence of polar groups on the surface of vulcanizates. Degradation of materials is also highlighted by the decrease in physical-mechanical properties, gel fraction and crosslinking degree. The best ageing behaviour was seen in the mixture containing a low amount of biodegradable filler such as starch and the worst behaviour was that of the control mixture, while the best results were obtained in the case of the mixture containing a lower amount of starch.

\section{References}

1. VOLINTIRU, T., IVAN, GH., Technological Bases for Processing Elastomers, Technical Press, Bucharest,1974.

2. *** ISO 188:2010

4. M. E. ABU-ZEID, Y. A. YOUSSEF, F. A. ABDUGRASQUL, J Appl Polym Sci., 32, 1986, p. 3345.

Fig.10. SEM micrographs

4. COLLISON, R., Starch retrogradation. In J . A. Radley, Starch and its derivatives (p. 198-202). London: Chapman and Hall. 1968.

5. SHUJ UN W., CAILI L., LESC., QING N., SHUO W. (2015-09-01), Comp Rev Food Sci Food Safety.ens 14, nr.5, 2015, p. 568.

6 ELIASSON A.-C., LARSSON K., Cereals in breadmaking: a molecular colloidal approach, CRC Press, 1993, p.126.

7. ENRIONE J., Mechanical Stability Of Intermediate Moisture Starch Glycerol Systems, Thesis Of Doctor of Philosophy, Biosciences University of Nottingham Sutton Bonington, 2005.

8. ORAVEC J., PRETO J., JURKOVIE P., MATYASOVSKY J ., CHODAK I., ORAVCOVÁ A., Ann. WULS - SGGW, For. and Wood Technol., 83, 2013, p.317

9. STELESCU M.D., GEORGESCU M., ALEXANDRESCU L., SONMEZ M., NITUICA M., The 17th International Multidisciplinary Scientific GeoConference SGEM 2017, Nano, Bio, Green and Space - Technologies for a Sustenable Future, Issue 62, Section: 26., 2017, p. 105.

10. SHEY J., IMAM S.H., GLENN G.M., ORTS W.J ., Ind Crops Prod., 24, no. 1,2006, p. 34.

11. *** http://www.meteoromania.ro

12. LOPEZ-MANCHADO M.A., HERRERO B., ARROYO M., Polym Int 52, no.7, 2003, p. 1070.

13. CHENAL J M, CHAZEAU L, GUY L, BOMAL Y, GAUTHIER C, Polymer, 48, no.4, 2007, p. 1042.

14. STELESCU, M. D., Leather Footwear J . 10, no. 3, 2010, p. 51

15. G. KRAUS, J Appl Polym Sci, 7, no.3, 1963, p. 861.

16. R.P. BROWN, T. BUTLER, Natural Ageing of Rubber, Changes in Physical Properties Over 40 Years, Rapra Technology Limited, Shawbury, Shrewsbury, United Kingdom, 2000.

17. ROY S., DE P.P., Polymer Testing, 11, no. 1, 1992, p. 3.

18.M. G. LOMELI-RAMIREZ, A. J. BARRIOS-GUZMÁN, S. GARCIAENRIQUEZ, J. RIVERA-PRADO, R. MANRÍQUEZ-GONZÁLEZ, BioResources, 9, no. 2, 2014, p. 2960.

19. KIZIL R., IRUDAYARAJ J., SEETHARAMAN K. J., Agric Food Chem, 50, no. 40, 2002, p. 3912.

20. MATHEW N. M., Chapitol 2, Natural Rubber, Rubber Technologist's Handbook, Edited by Sadhan K. De and Jim R. White, Rapra Technology Limited, 2001

21.HAMED G. R., Engineering with Rubber, A. N. Gent (Ed.), 2nd edition, 2001, Hanser, p. 27

Manuscript received: 10.11 .2017 